\title{
El Servicio Europeo de Acción Exterior: ¿solo una hermosa fachada para la inanidad?
}

\author{
Cesáreo Gutiérrez Espada \\ Catedrático de Derecho Internacional Público y Relaciones Internacionales \\ Facultad de Derecho, Universidad de Murcia
}

Sumario: I. El Tratado de Lisboa.-II. El proceso de negociación del SEAE. 1. Comisión, Consejo y Estados miembros. 2. El Parlamento Europeo.-III. La Decisión del Consejo de 26 de julio de 2010 por la que se establece la organización y el funcionamiento del Servicio Europeo de Acción Exterior (2010/427/UE). - IV. Problemas claves del mismo. 1. Composición del SEAE. 2. Las delegaciones de la Unión. 3. Implicaciones para España. - V. En suma (...).

Resumen: Partiendo de algunas consideraciones fundamentales sobre el alcance del las innovaciones del Tratado de Lisboa en materia de relaciones exteriores y PESC, como base para una mejor comprensión del Servicio Europeo de Acción Exterior (SEAE). A continuación, tras reflexionar sobre el proceso político que dio forma a la Decisión Final del Consejo, el artículo analiza desde una perspectiva formal e institucional, aunque crítica, la naturaleza del SEAE, así como los diversos problemas que plantea su puesta en acción, y las expectativas que pueden albergarse sobre su operatividad. El artículo concluye, en suma, que el nuevo servicio difícilmente podrá rescatar a la Unión Europea de su inmovilismo en materia de política exterior.

Palabras clave: UE, SEAE, Tratado de Lisboa, PESC, relaciones exteriores.

Abstract: This article starts with a reflective assessment of the limits and scope of the innovations of the Lisbon Treaty in the field of external relations and CFSP, as a basis for s better understanding of the European External Action Service (EEAS). Then, after reflecting on the political process that shaped Council's Final Decision, it examines from a critical perspective the EEAS's main legal and institutional dimensions, as well as some of the possible complications to foreseen in the moment of its operational deployment. The article concludes, in short, that the new service is unlikely to rescue by itself the EU's current impasse in its international role.

Keywords: EU, EEAS, Lisbon Treaty, CFSP, external relations. 


\section{EI Tratado de Lisboa}

1. Amén de la decisión de crear la figura del Alto Representante de la Unión para los Asuntos Exteriores y la Política de Seguridad, el Tratado de Lisboa $(2007)^{1}$ establece un Servicio Europeo de Acción Exterior $(\mathrm{SEAE})^{2}$.

En el Derecho de la Unión anterior a la reforma operada por el Tratado de Lisboa (2007), el Consejo contaba con la asistencia de una Secretaría General, dirigida por el Secretario General y Alto Representante para la PESC, al que asistía a su vez un Secretario General Adjunto (TCE artículo 207.2); en la Secretaría General existían distintas Direcciones Generales, una de ellas la encargada de los asuntos exteriores y políticas militares (PESC, PESD, ampliación, comercio y cooperación para el desarrollo), añadiéndose a estas la llamada Unidad Política, el Centro de Situación y el Estado Mayor de la Unión Europea ${ }^{3}$. La Comisión, por su parte, contaba con más de veinte Direcciones Generales, seis de las cuales se ocupaban directamente de cuestiones ligadas a las relaciones exteriores (DG de Relaciones Exteriores, DG de Comercio, DG de Desarrollo, DG

1 Tratado de Lisboa por el que se modifican el Tratado de la Unión Europea y el Tratado constitutivo de la Comunidad Europea, firmado en Lisboa el 13 de diciembre de 2007 (DO 2007/C 306/01, 17 de diciembre).

2 Artículo 27.3 del TUE reformado (versiones consolidadas del Tratado de la Unión Europea y del Tratado de Funcionamiento de la Unión Europea, DO 2008/C 115/01, 9 de mayo).

${ }^{3}$ La «Unidad de Planificación de la Política y de Alerta Rápida», su nombre completo, fue creada en 1998, de acuerdo con la decisión de la Conferencia de Ámsterdam (1996-1997) de establecer una unidad con la misión de observar y analizar la evolución de la situación en ámbitos de la PESC, evaluar ésta, determinar las materias en las que la PESC podría centrarse y alertar rápidamente ante hechos o situaciones que pudieran tener repercusiones importantes para la PESC.

El Centro de Situación de la Unión Europea se creó por el Alto Representante en el seno de la Unidad Política aunque más tarde logró su autonomía. Nacido como un centro de análisis de la Inteligencia (se identificó por algunos como el embrión de la CIA de la Unión), desde enero de 2005 se ocupa tanto de la inteligencia «externa» (amenazas exteriores a la Unión Europea) como de la «interna» (terrorismo por ejemplo). Hoy viene a ser un centro de intercambio de información y apoyo a las políticas de la Unión. Elabora evaluaciones destinadas al Comité Político y de Seguridad y para el Alto Representante, pero también y junto a estas funciones propias del segundo pilar ejerce cometidos en el tercero de la Cooperación Policial y Judicial en materia Penal (ya he mencionado sus actividades de inteligencia en materia de terrorismo).

El Estado Mayor de la Unión Europea nace en el 2001 ( $D O$ L 27, de 30 de enero) y está formado por 200 personas de las que 159 son oficiales de los Ministerios de Defensa de los Estados miembros en comisión de servicios. El Estado mayor asesora al Consejo y al Alto Representante en temas militares, efectúa evaluaciones y recomendaciones sobre la gestión de crisis y ejerce, asimismo, funciones de alerta temprana y planificación. 
sobre la Ampliación, Oficina Europea de Ayuda Humanitaria y Oficina de Cooperación).

Durante la Convención, que dio vida al Tratado Constitucional (2004), se barajó la idea de crear un cuerpo diplomático propiamente europeo, agrupando los distintos servicios del Consejo y la Comisión, que habría de encargarse de la representación en el exterior de la Unión. Se sugirió, incluso, la creación de una Escuela o Academia Diplomática Europea ${ }^{5}$. Ninguna de estas iniciativas prosperó finalmente por la presión del Reino Unido y otros Estados grandes, adoptando el Tratado Constitucional (2004) una visión menos ambiciosa.

El Tratado de Lisboa (2007) recoge las disposiciones que estableciera su antecesor «sin alterar una sola coma en su regulación», se ha escrito ${ }^{6}$. El artículo 27.3 del TUE reformado prevé un Servicio Europeo de Acción Exterior que estará formado por funcionarios de los servicios competentes de la Secretaria General del Consejo y de la Comisión así como por personal de los cuerpos diplomáticos nacionales. Este Servicio nace para apoyar al Alto Representante y trabajaría en colaboración con los órganos diplomáticos y consulares de los Estados miembros. Repárese entonces en que la concepción de este nuevo mecanismo responde a la noción de «diplomacia común europea» expuesto por el Parlamento ya en el año $2000^{7}$ y que implicaba una composición híbrida (comunitaria y personal de los Estados miembros) así como una estrecha cooperación entre esta diplomacia común y los servicios diplomáticos nacionales ${ }^{8}$. Se descartó por el Tratado Constitucional (2004), y el de Lisboa (2007) lo mantuvo, la creación de lo que podríamos denominar una «diplomacia única o estric-

${ }^{4}$ Proyecto de Tratado por el que se instituye una Constitución para Europa. Adoptado por consenso por la Convención Europea el 13 de junio y el 19 de julio de 2003 y presentado al Consejo Europeo en Roma - 18 de julio de 2003 (CONV 850/03), Bruselas, 18 de julio de 2003; Tratado por el que se establece una Constitución para Europa (DO n. ${ }^{\circ} \mathrm{C} 310$ de 16 diciembre 2004).

5 Sobre las propuestas y matices formuladas durante los trabajos preparatorios del Tratado Constitucional en este ámbito, vid. FERNÁNDEZ SOLA, N., «El Servicio de Acción Exterior de la Unión Europea» en Documento de Trabajo del Real Instituto Elcano de Estudios Internacionales y Estratégicos, n. $^{\circ}$ 46, Real Instituto Elcano de Estudios Internacionales y Estratégicos, Madrid, 10/11/2008, pp. 7-10.

${ }^{6}$ ALDECOA LUZÁRRAGA, F. y GUINEA LLORENTE, M., La Europea que viene: el Tratado de Lisboa, Marcial Pons, Madrid-Barcelona-Buenos Aires, 2008, p. 221.

7 A5-0210/2000 (resolución sobre el establecimiento de una diplomacia común para la Comunidad Europea, de 5 de septiembre de 2000).

8 Vid. ALDECOA LUZÁRRAGA, F.: «La diplomacia común europea: un instrumento para una política exterior alternativa» en Soberanía del Estado y Derecho Internacional: Homenaje al profesor Juan Antonio Carrillo Salcedo, Servicio de Publicaciones de las Universidades de Córdoba, Sevilla y Málaga, Sevilla, 2005, tomo I, pp. 117-136. 
tamente europea» que tuviera la ambición de reemplazar las diplomacias nacionales.

Según determina el artículo 27.3 del TUE reformado, el Servicio se pondrá en marcha por decisión del Consejo, a propuesta del Alto Representante, previa consulta al Parlamento Europeo y previa aprobación de la Comisión9. No obstante, la Declaración (número 15) relativa al artículo 27 del TUE aprobada en la CIG determinó que «en cuanto se haya firmado el Tratado de Lisboa [lo que sucedió, como se recordará, el 13 de diciembre de 2007], el Secretario General del Consejo, Alto Representante de la PESC, la Comisión y los Estados miembros deberían comenzar los trabajos preparatorios relativos al Servicio Europeo de Acción Exterior».

2. La creación del SEAE no fue recibida con alegría por la unanimidad de la doctrina. Algunos criticaron su heterogénea composición y no le guardaban fe alguna en cuanto a que pueda convertirse en un mecanismo capaz de respaldar con eficacia la labor de quien el abandonado Tratado Constitucional (2004) llamaba Ministro de Asuntos Exteriores de la Unión; otros lo valoraron positivamente viendo en él una «mente única» que dará a la formulación de la PESC más coherencia y visibilidad ${ }^{10}$.

Tampoco los Estados miembros parecían tener de este Servicio la misma consideración. Ello explica por qué la Conferencia Intergubernamental (CIG) de Lisboa aprobó dos declaraciones, las números 13 y 14, relativas a la PESC en las que, aunque sea entre líneas, pueden descubrirse los recelos con los que si no todos sí al menos parte de los miembros de la Unión recibían esta nueva figura. De las dos, una es más genérica y menos cautelosa que la otra; la declaración número 14, en particular, dice así:

«la Conferencia subraya que las disposiciones referentes (...) al Servicio Europeo de Acción Exterior, no afectarán a las bases jurídicas, responsabilidades y competencias existentes de cada Estado miembro en relación

9 El párrafo segundo del artículo 24 del TUE reformado determina que el Consejo Europeo y el Consejo «deberán pronunciarse por unanimidad salvo cuando los Tratados dispongan otra cosa» en cuanto a la «definición y aplicación» de la «PESC» (no dice como en el Tratado Constitucional que todas las decisiones adoptadas respecto de este capítulo...). Si entendemos que la decisión en concreto a la que se refiere el artículo 27.3 del TUE reformado y en cuya virtud el Consejo debe regular «la organización y el funcionamiento del servicio europeo de acción exterior» constituye una manifestación de «definición y aplicación de la PESC», dicha decisión debe adoptarse por unanimidad.

10 Véanse los autores y matices que respecto de ambas posiciones se mencionan por ALDECOA LUZÁRRAGA, F. y GUINEA LLORENTE, M., La Europa que viene..., op . cit., nota 6, p. 223. 
con la formulación y conducción de su política exterior, sus relaciones con terceros países y su participación en Organizaciones internacionales, incluida la pertenencia de un Estado miembro al Consejo de Seguridad de las Naciones Unidas».

Es decir, que a fecha de hoy los Estados miembros no renuncian a nada de lo que su soberanía nacional les da en política exterior. Declaraciones, éstas, por lo demás, que no son sino la crónica anunciada de la complejidad de los debates y la dificultad de la decisión que habría que tomar para concretar todas las cuestiones que la puesta en marcha de este Servicio planteaba.

3. El SEAE no es una institución de la Unión Europea, ni una agencia ni tampoco un organismo adscrito al Consejo o (como prefería el Parlamento Europeo) la Comisión. ¿Qué es entonces?, pues un «servicio», un, se ha calificado entre nosotros, «servicio sui generis» ${ }^{11}$ dependiente del Alto Representante.

En todo caso, como anteriormente he afirmado, eran numerosas e importantes las interrogantes que la concreción de la regulación que para este Servicio determinó el Tratado de Lisboa exigía responder. Enumeremos algunas $^{12}$ : ¿debería incluir la mayor parte (por no decir todos) los servicios competentes de la Comisión o solo algunas de sus unidades?; y en cuanto a los servicios del Consejo, ¿también deberían formar parte del SEAE los de carácter puramente militar como es el caso del Estado Mayor de la Unión Europea o aquellos que, además de en el segundo pilar, tienen también un papel que jugar en el tercero, caso del Centro de Situación de la Unión Europea; ¿cuántos diplomáticos de los Estados miembros tendrían en él cabida?; ¿cómo delimitar las competencias entre Servicio Europeo y los órganos diplomáticos y consulares de los Estados miembros al menos en ciertos temas?; y, desde un enfoque más egoísta, ¿qué implicaciones tendrá la puesta en marcha de este Servicio para nuestro país?

4. El Consejo Europeo de diciembre de 2004, posterior a la firma del Tratado Constitucional (2004), invitó al Secretario General y Alto Representante de la PESC así como a la Comisión a preparar un informe sobre

11 PÉREZ BERNÁRDEZ, C., «Hacia el complejo establecimiento de un Servicio Europeo de Acción Exterior: las futuras embajadas de la Unión Europea» en ALDECOA, F., SOBRINO, J.M., GONZÁLEZ, L.N., PASTOR, A., CORNER, J., HERRANZ M. y PÉREZ C. (coordinadores), Los Tratados de Roma en su cincuenta aniversario. Perspectivas desde la Asociación Española de Profesores de Derecho Internacional y Relaciones Internacionales, AEPDIRI-Marcial Pons, Madrid-Barcelona-Buenos Aires, 2008, p. 1.354.

12 No son las únicas: vid. PIRIS, J.C., El Tratado Constitucional para Europa. Un análisis jurídico, Cátedra Internacional OMC/Integración regional y Marcial Pons, Madrid-Barcelona, 2006, pp. 190-191. 
el SEAE en el que se concretaran sus elementos clave, incluyendo su contenido y estructura ${ }^{13}$. El Informe de situación sobre el Servicio Europeo de Acción Exterior se publicó en junio de $2005^{14}$. También el Parlamento Europeo adoptó, a finales del mes anterior, una resolución sobre el mismo ${ }^{15}$.

Tras conocerse los resultados de los referendos de Francia y Países Bajos (mayo y junio de 2005), los trabajos al respecto se suspendieron. Una vez firmado, el 13 de diciembre de 2007 como sabemos, el Tratado de Lisboa se reanudaron los trabajos, pero el referéndum irlandés del 2008 incidió de nuevo negativamente en una marcha regular del proceso.

El Consejo Europeo de Bruselas (10 y 11 diciembre 2009) invitó a la Alta Representante para Asuntos Exteriores y Política de Seguridad, Catherine Ashton, a preparar la organización y funcionamiento del SEAE,

«con vistas a su adopción (...) antes de finales de abril de $2010{ }^{16}$.

\section{El proceso de negociación del SEAE}

5. El que fuera Alto Representante para la PESC de la Unión, Javier Solana Madariaga, respondía no hace mucho a un periodista español que le preguntaba qué sería del SEAE afirmando que este solo lo sería de verdad en el caso en que la Comisión y los Estados miembros con más experiencia en política exterior «se crean de verdad el servicio exterior y lo asuman como propio» ${ }^{17}$.

No parece, a la luz del proceso de negociación que ha conducido al establecimiento del mencionado SEAE, que esto haya sido así (...)

\section{Comisión, Consejo y Estados miembros}

6. Con la creación del cargo de Alto Representante para Asuntos Exteriores y Política de Seguridad la Unión Europea ya no estará represen-

13 Conclusiones de la Presidencia, puntos 71-73 (Boletín de la Unión Europea, 12-2004).

14 Servicio Europeo de Acción Exterior. Informe de situación conjunto dirigido al Consejo Europeo por el Secretario General y Alto Representante y la Comisión, Consejo de la Unión Europea, Bruselas, 9 de junio de 2005 (CAB 24 RELEX 304), 9956/05, pp. 1-12.

15 Resolución del Parlamento Europeo sobre los aspectos institucionales del Servicio Europeo de Acción Exterior, de 26 de mayo de 2005 (DO C 117E/233).

16 Conclusiones de la Presidencia (CO EUR/6, CONCL 4), Bruselas 11 de diciembre de 2009, p. 3 (párrafo 5).

${ }_{17}$ Reivindicación de la Política. Veinte años de relaciones internacionales. Javier Solana, en conversación con Lluis Bassets, Debate, Barcelona, 2010, p. 146. 
tada en temas de política exterior por dos personas, sino por una sola. Los puestos desempeñados por el Comisario de Asuntos Exteriores y por Javier Solana Madariaga, Comisionado para Exterior del Consejo, quedaban unificados en dicha figura. Eso en principio parecía positivo, pues suponía la reducción del número de interlocutores de la Unión Europea en materia de Asuntos Exteriores. Con todo, si bien se piensa, tampoco daba pie a lanzar las campanas al vuelo.

Y es que el Tratado de Lisboa (2007) no ha realizado un cambio de sistema. La Política Exterior y de Seguridad sigue estando exclusivamente en manos de los Estados miembros; tras su entrada en vigor y como ocurría antes de la misma, todas las decisiones esenciales deben adoptarse por unanimidad. Así, el Consejo, en cuanto órgano de representación de los Estados miembros, es responsable de la Política Exterior y de Seguridad Común (PESC) y la Comisión Europea lo es de las tareas, no menos significativas en el ámbito de la política exterior, de la política de ampliación y vecindad, de la política de desarrollo, como la ayuda humanitaria, y, no menos importante, de la política comercial. Esto es, la misma estructura duplicada de siempre, la misma, la misma, la misma (...).

Se ha llegado a decir, incluso, que la figura del Alto Representante no es sino «un elemento auxiliar, cuando no una engañifa» ${ }^{18}$, que encubre que los Estados miembros tampoco lograron ponerse de acuerdo, al concertar el Tratado de Lisboa (2007), en hacer realmente común la Política Exterior y de Seguridad. Y resulta que la base del Alto Representante la constituye el $\operatorname{SEAE}(\ldots)$.

7. Desde el inicio mismo de las negociaciones para la concreción de las disposiciones que sobre este Servicio estableciera el Tratado de Lisboa (2007) se ha visto que ni la Comisión, ni el Consejo, ni los Estados miembros querían renunciar a nada de lo que tenían, en el ámbito de la Acción Exterior de la Unión.

8. La «primera en la frente» contra el SEAE vino de manos del Presidente de la Comisión. Como responsable del diseño de las carteras de sus Comisarios, sustrajo los ámbitos en materia exterior de la Política Europea de Vecindad del Comisario de Asuntos Exteriores (al que se hallaban encomendados en la anterior Comisión) para adjudicárselos al Comisario de Ampliación. Así, quienes habían creído que el Alto Representante iba a asumir todas las tareas del anterior Comisario de Asuntos Exteriores, se equivocaban (...). El mensaje que el Sr. Durao Barroso

18 WEISS, S., El Servicio Europeo de Acción Exterior: mucho ruido y pocas nueces, Spotlight Europe Fundación Bertelsmann Stiftung, junio 2010, pp. 1-8, p. 2 http://www. bertelsmann-stiftung.de/cps/rde/xbcr/SID-EF0F21D8-C5DE20AE/bst/spotlight_europe_El_ Servicio_Europeo_de_Accion_Exterior_KLEIN.pdf (última consulta 14/02/2011) 
transmitía era meridiano en su claridad: La Comisión no estaba dispuesta a renunciar a sus competencias en materia de política exterior en beneficio del SEAE. Quería, en definitiva, seguir desempeñando también en el futuro su propio papel en estos temas. Es un riesgo sin duda contra el que ya se ha advertido, porque si la Comisión decide asumir una posición de excesivo protagonismo, puede que a los grandes países el Servicio en cuestión ya nos les interese; ¿y qué tendríamos entonces?, pues un poco más de lo que hay, sí, pero no desde luego lo suficiente para hacer de la Unión una actor global capaz de afrontar los enormes retos de las relaciones internacionales contemporáneas. $\mathrm{O}$, en las palabras de respuesta de Javier Solana a una de las preguntas de su entrevistador Lluis Bassets:

«Será un servicio exterior, pero no el mejor posible, aunque sea mejor que lo que hoy tiene la Comisión sola» ${ }^{19}$.

Pero hay más. La Comisión invierte anualmente en sus programas en los ámbitos de la prevención de conflictos, protección de los derechos humanos y de la democracia y política de desarrollo en su sentido más amplio casi 12.000 millones de euros, siendo la financiación del Consejo para la PESC/PESD de 250 millones. Lo lógico sería, dada la naturaleza y finalidades de su cargo, que la planificación estratégica para la asignación de recursos a estos programas correspondiera al Alto Representante, ocupándose la Comisión de ejecutar estos. El Alto Representante, cabeza del SEAE, debería (siguiendo, desde luego, las prioridades políticas acordadas) poder decidir cuantos fondos deberán dedicarse y a qué en el futuro. No será así. El SEAE realizará, por el contrario, la programación de los correspondientes instrumentos financieros ${ }^{20}$ por encargo y bajo la supervisión del correspondiente Comisario ${ }^{21}$. Con ello la Alta Representante se ha doblegado ante la Comisión, al aceptar que su intervención habrá de limitarse a colaborar en la planificación estratégica y actuar únicamente

19 Reivindicación de la Política... op. cit., nota 17, p. 147.

${ }^{20}$ En el párrafo 2 de este artículos, la Decisión relaciona los siguientes instrumentos de ayuda exterior: El Instrumento de Cooperación al Desarrollo, el Fondo Europeo de Desarro1lo, El Instrumento Europeo para la Democracia y los Derechos Humanos, El Instrumento Europeo de Vecindad y Asociación, el Instrumento de Cooperación con los Países Industrializados, El Instrumento de Cooperación en materia de Seguridad Nuclear y el Instrumento de Estabilidad, en relación con la asistencia prevista en el artículo 4 del Reglamento (CE) núm. 1717/2006.

21 Vid. Decisión del Consejo de 26 de julio de 2010 por la que se establece la organización y el funcionamiento del Servicio Europeo de Acción Exterior (2010/427/UE), Diario Oficial de la Unión Europea L 201, 3.8.2010, artículo 9, párrafos 3, 4 y 5. 
desde una función de coordinación ${ }^{22}$. La decisión en caso de litigio corresponde a aquélla.

9. Tampoco el Consejo mostró demasiado entusiasmo en proporcionar mayor «visibilidad» a la Unión como actor global ${ }^{23}$ mediante un SEAE estructurado de manera eficiente y desmontando estructuras duplicadas de Consejo y Comisión (...).

Por el contrario, en el Consejo se adoptaron las medidas precisas para que, durante la transferencia prevista al SEAE de los pertinentes departamentos del Consejo, todo quedara como hasta entonces. Y antes de que la Alta Representante presentase su primer borrador propio para el Servicio en estudio, el Consejo ya la había puesto ante hechos consumados al presentarle una nueva Dirección para la Planificación y la Gestión de Crisis, en la que se integraban los instrumentos civiles y militares del Consejo establecidos para responder ante situaciones de crisis. A propuesta de éste, la Dirección en cuestión debería transferirse al SEAE como unidad especial con un estatuto de personal propio, al igual que el Estado Mayor para la Capacidad Civil de Planificación y Ejecución, el Estado Mayor Militar de la Unión Europea y el Centro Conjunto de Situación para el Análisis de la Inteligencia.

Para la Comisión y el Parlamento Europeo, sin embargo, las ideas que el Consejo logró incluir en el borrador de Decisión de 25 de marzo de 2010, despertaron el temor de que las competencias otorgadas a la Comisión en el pasado en el ámbito de la prevención de conflictos, la reacción ante las crisis y el seguimiento de los conflictos, pudieran «sacarse» del método comunitario. Y en el Parlamento Europeo se exigió reunir al menos las correspondientes competencias de la Comisión y del Consejo en una misma y única Dirección General en el SEAE.

10. Aunque tras el informe sobre el SEAE de la Presidencia sueca (octubre 2009), que ya exponía de manera precisa la estructura, composición y forma de trabajo de aquél, la mayoría de Jefes de Estado y de Gobierno pensaron que, después de un segundo referéndum irlandés con resultado positivo, la ejecución de este plan mediante una propuesta de decisión definitiva por el Alto Representante sería un mero trámite formal, no fue realmente así. Los Estados miembros no contaron con la oposición a este borrador de la Comisión y muy en particular del Parlamento Europeo. Tampoco

22 Ibid. Artículo 9.1 y 9.2

${ }^{23}$ Sobre la noción de «visibilidad» de la Unión, vid. ad ex. FERNÁNDEZ LIESA, C.R., «Visibilidad de la acción exterior europea en el nuevo Tratado de Lisboa» en MARTÍN Y PÉREZ DE NANCLARES, J. (coordinador): El Tratado de Lisboa. La salida de la crisis constitucional, Asociación de Profesores de Derecho Internacional y Relaciones Internacionales (APDIRI)-Iustel, Madrid, 2008, pp. 349-360. 
prestaron, por lo demás, excesiva atención al SEAE, pues la crisis financiera y económica y, en último término, los problemas de la deuda y del euro impusieron su peso.

El relativo interés que respecto de este nuevo instrumento demostraron los Estados miembros constituye, probablemente, una expresión de la calculada ambigüedad que en materia de política exterior y de seguridad éstos siguen, a la postre, manteniendo. El hecho de que Europa necesite encontrar respuestas comunes a los retos cada vez más complejos de las modernas relaciones internacionales, jugó un papel insignificante durante las negociaciones mantenidas en el proceso de establecimiento del SEAE. Mucho menor en todo caso que las preocupaciones e intereses propiamente nacionales. Baste recordar al respecto que solo a instancias del Parlamento Europeo se ha incluido en el organigrama del SEAE un departamento de planificación estratégica ${ }^{24}$.

Por ejemplo, de la preocupación de Alemania por el SEAE lo único que se supo, y al cabo de no poco tiempo, fue una carta de su Ministro de Asuntos Exteriores a la Alta Representante, en la que se exigía que el alemán fuera idioma oficial en el Servicio ${ }^{25}$. En Gran Bretaña, otro Grande, el SEAE nunca encontró grandes partidarios; ya había dejado claro durante las negociaciones del Tratado de Lisboa que no estaba dispuesto a tolerar merma alguna de su soberanía en temas de PESC y PCSD ${ }^{26}$. La preocupación, por su parte, de los Estados miembros de la Unión más pequeños se centró en que sus diplomáticos no quedaran relegados por los más grandes a la hora de distribuir los puestos: exigieron, sin éxito, un quórum para ellos, pero si consiguieron introducir en el proyecto de decisión un párrafo en el sentido de que la composición del Servicio debía estar compensada geográficamente 27 .

En rigor, solo Francia se implicó a fondo en este nuevo Servicio, intentando influir en su estructura. De hecho, el poderoso Secretario General ejecutivo ( «que gestiona el SEAE» en su conjunto, aunque actúe bajo la autoridad del Alto Representante) es de inspiración francesa ${ }^{28}$. El que en octubre de 2010 la Alta Representante decidiese el nombramiento precisamente de un francés, Pierre Vimont, como Secretario General ejecutivo del Servicio y

${ }^{24}$ Artículo 4, párrafo 3, letra b) de la Decisión de 26 de abril de 2010, op. cit., nota 21, Vid. asimismo parágrafo 16, letra A de este mismo trabajo.

25 WEISS, S., El Servicio Europeo..., op. cit. (nota 18), p. 6.

${ }^{26}$ Por ejemplo, la pretensión de brindar al SEAE la posibilidad de asumir cometidos consulares en terceros países fue suprimida a causa de la oposición del Gobierno de Su Graciosa Majestad. Vid. infra parágrafos 21-24 de este trabajo.

27 Vid. infra parágrafos 19-20.

28 Artículo 4.1 de la Decisión que lo establece, op. cit., nota 21. 
los comentarios realizados al respecto por el Ministro de Asuntos Exteriores de ese país ${ }^{29}$ refuerzan la idea de que Francia es hoy, entre actuales Estados miembros de la Unión, uno de los principales valedores del SEAE.

\section{El Parlamento Europeo}

11. Tras la reanudación de los trabajos para la concreción del SEAE, una vez que el Consejo anunció la celebración de un segundo referéndum en Irlanda, el Parlamento Europeo recordaba al Consejo, en una nueva resolución (octubre de 2009), la necesidad de un diálogo permanente con él si se quería una puesta en funcionamiento eficaz del Servicio y la garantía de que el mismo contara con los recursos financieros necesarios. El Parlamento reiteró, asimismo, que el SEAE debía integrarse en la estructura administrativa de la Comisión, así como estar sujeto a las decisiones del Consejo (en los ámbitos de la PESC y la PCSD) y de la Comisión (en el ámbito de dimensión exterior de las políticas comunitarias y, en general, de las relaciones exteriores comunes).

El Parlamento manifestaba ya también, de cara a la negociación de la Decisión del Consejo, las posiciones que entendía irrenunciables ${ }^{30}$.

29 Declaraciones, de 26 de octubre de 2010, de Bernard Kouchner, MINISTÉRE DES AFFAIRES ÉTRANGERES, Nombramiento de Pierre Vimont como secretario general ejecutivo del Servicio europeo para la Acción exterior de la Unión europea, République Française, 26 de octubre de 2010, http://www.diplomatie.gouv.fr/es/article_imprim.php3?id_ article $=8586$ (última consulta 02/12/2010)

30 Primero, que todo el personal del SEAE debería poseer el mismo carácter temporal o permanente y los mismos derechos y obligaciones independientemente de su origen y que deberían disponer de cierta independencia objetiva en el marco de las instrucciones emanadas de las responsabilidades definidas en los Tratados. Segundo, que deberían otorgarse al alto representante y vicepresidente de la Comisión las competencias de autoridad facultada para proceder a los nombramientos en el SEAE. Tercero, que debería incluirse en la Decisión la estructura de organización del servicio y que el organigrama se debería aprobar como parte del presupuesto de la Comisión (gastos administrativos) en el marco del procedimiento presupuestario anual. Cuarto, que el SEAE debería estar dirigido por un director general responsable ante el alto representante y vicepresidente de la Comisión. Quinto, que el SEAE debería ramificarse en diferentes direcciones especializadas para cada uno de los distintos ámbitos geoestratégicos y en otras direcciones competentes para las cuestiones relativas a la política de seguridad y defensa, la gestión civil de crisis y asuntos multilaterales y horizontales, incluidos los derechos humanos y las cuestiones administrativas. Sexto, que el alto representante y vicepresidente de la Comisión debería comprometerse a informar a las comisiones de Asuntos Exteriores y de Desarrollo del Parlamento Europeo sobre sus nombramientos para altos cargos del SEAE, y tendría que aceptar que se celebraran audiencias de los candidatos, si la Eurocámara así lo decidiera (JÁUREGUI ATONDO, R., El Parlamento Europeo: un actor decisivo en las negociaciones sobre la creación del Servicio Europeo de Acción Exterior, ARI 147/2010, 15/10/2010, pp. 1-6 [p. 3], 
12. El 23 de octubre de 2009 se presentó el documento de base, elaborado por la Presidencia del Consejo y los Estados miembros. A fin de elaborar la propuesta legislativa y partiendo de ese texto y de las recomendaciones del Parlamento Europeo, la Alta Representante creó un grupo de trabajo, formado por doce expertos provenientes del Consejo, la Comisión y de las presidencias rotatorias. La propuesta de Decisión se adoptó el 25 de marzo de 2010.

13. El 26 de abril de 2010, el Consejo de Asuntos Generales llegaba a un acuerdo político global respaldado por la Comisión Europea. No obstante, y merced a los nuevos poderes que el Tratado de Lisboa (2007) le asignó, el Parlamento Europeo debía dar asimismo su aprobación a los Reglamentos sobre el presupuesto y el estatuto del personal de este nuevo SEAE.

Los tres grandes grupos políticos que en él se integran (Partido Popular Europeo, Grupo de la Alianza Progresista de Socialistas y Demócratas y Grupo de la Alianza de los Demócratas y Liberales por Europa) trabajaron conjuntamente para incluir en el proyecto de Decisión sus posiciones, añadiendo incluso, a las que ya se señalaron, alguna exigencia más ${ }^{31}$. El 21 de junio en Madrid, la Alta Representante, la Presidencia española de la Unión y los representantes del Parlamento Europeo llegaron a un acuerdo político sobre la organización y el funcionamiento del SEAE, acordándose además dos declaraciones de la Sra. Ashton sobre su responsabilidad política y sobre la estructura básica de la administración central del Servicio ${ }^{32}$.

El 8 de julio de 2010, por 549 votos a favor, 78 en contra y 17 abstenciones, el Parlamento Europeo aprobó la propuesta de la Alta Representante en su versión modificada. Y lo hizo consiguiendo que el texto final recogiera sus ideas prioritarias: el respeto del método comunitario y del papel de la Comisión, a través de un vínculo estrecho entre el SEAE y la Comisión Europea, y la garantía de un control político y presupuestario por parte del Parlamento sobre el SEAE. Además, el texto final contempla, a juicio de uno de sus diputados ${ }^{33}$, la mayoría de las peticiones del Parlamento:

31 Mayores competencias para el SEAE, alguna de las cuales la Comisión había pretendido escamotear (la política de desarrollo, la ayuda humanitaria o la política de vecindad), una distribución equitativa de nacionalidades en el personal del Servicio, el nombramiento de delegados políticos con responsabilidad política para asistir a la Alta Representante, y un cuerpo exterior en el que al menos la mitad de sus componente procediese de la Comisión.

32 Declaración del Parlamento Europeo, del Alto Representante de la Unión para Asuntos Exteriores y Política de Seguridad y del Consejo sobre el SEAE, COMISIÓN EUROPEAREPRESENTACIÓN EN ESPANA.

33 JÁUREGUI ATONDO, R.: El Parlamento Europeo: un actor decisivo..., op. cit., nota 30 , pp. 4-5. 
- Que aunque la contratación del personal del SEAE se base en los méritos, el equilibrio geográfico y el de género sean tenidos en cuenta en los nombramientos de los Jefes de las Delegaciones de la Unión y que la Comisión Europea participe en el proceso de selección de éstos, aunque sea la Alta Representante quien tome las decisiones finales.

- Que al menos un 60\% del personal del SEAE esté formado por funcionarios de la Unión, lo que garantiza la identidad comunitaria del servicio, y que los funcionarios de los servicios diplomáticos nacionales, que representarán un tercio del personal, sean agentes temporales por un máximo de ocho años con la posibilidad de renovarles dos años más. Así, el 1 de enero de 2011, un total de 1.525 funcionarios de la Comisión y la Secretaría General del Consejo serán transferidos al SEAE y se crearán 100 nuevos puestos.

- Que el control político y presupuestario sobre el SEAE en su conjunto del Parlamento esté garantizado mediante los derechos de descarga (control de la gestión presupuestaria). Además, aunque el presupuesto operacional será responsabilidad de la Comisión, la Alta Representante se ha comprometido a que el Parlamento reciba un documento que explique qué partes del presupuesto están consagradas a las acciones exteriores, incluyendo los planes de establecimiento de las Delegaciones de la Unión y el gasto de las acciones desglosado por país y misión. El presupuesto administrativo del SEAE entrará en una nueva sección denominada «Servicio Europeo de Acción Exterior». En el contexto del tema de la financiación de este nuevo Servicio, puede ser útil mencionar que el martes 30 de noviembre de 2010, la Comisión ha lanzado una consulta pública para recabar ideas de los expertos sobre cómo financiar el Servicio a partir del $2013^{34}$.

- Que los representantes especiales de la Unión y los jefes de las Delegaciones en los países y organizaciones que el Parlamento considere «estratégicamente importantes», comparezcan ante la Comisión de Asuntos Exteriores. Además, ésta comisión y la de Presupuestos tendrán un mayor control sobre las misiones de la PESC financiadas con presupuesto de la Unión. Todos estos puntos han quedado reflejados en la declaración sobre responsabilidad política de la Alta Representante que esta ha efectuado acompañando a la Decisión.

- Que en el organigrama figure, por debajo del Alto Representante, un Secretario General ejecutivo y dos secretarios adjuntos.

${ }^{34}$ MSG, Bruselas lanza una consulta pública sobre cómo financiar el Servicio de Acción Exterior más allá de 2010, Intereconomía, Madrid, 30/11/2010, http://www.intereconomia. com/print/399765 (última consulta 02/12/2010). 
- Y, por último, los diputados han introducido en la Decisión la obligatoriedad de presentar antes de 2011 un informe, al Parlamento, al Consejo y a la Comisión, sobre el funcionamiento del SEAE y a mediados de 2013, una evaluación de su organización y funcionamiento.

\section{La Decisión del Consejo de 26 de julio de 2010 por la que se establece la organización y el funcionamiento del Servicio Europeo de Acción Exterior (2010/427/UE)}

14. La Decisión por la que se crea el SEAE se adoptó por el Consejo de Asuntos Exteriores, el 26 de julio de $2010^{35}$. Y este mismo órgano y con idéntica formación aprueba, el 25 de octubre siguiente, los Reglamentos financieros y de personal del $\mathrm{SEAE}^{36}$, por lo que éste podrá estar funcionando en diciembre de 2010 o principios de 2011.

15. El SEAE es una auténtica administración que servirá de apoyo a la figura del Alto Representante, estando bajo su autoridad, y con sede en Bruselas. Es un organismo autónomo de la Unión Europea, separado de la Comisión y de la Secretaría General del Consejo. Está compuesto por una administración central y por las Delegaciones de la Unión en el extranjero. La elección del Secretario General Ejecutivo, y de los dos vicesecretarios, cargos de gran importancia ${ }^{37}$, ya se ha producido como sabemos. El francés Pierre Vimont ${ }^{38}$, bajo la dirección de la Alta Representante, será el encargado en cuanto Secretario General ejecutivo del SEAE de la gestión administrativa y financiera, así como de la coordinación entre la estructura central y las Delegaciones en el exterior.

Aunque el SEAE también debe asistir al Presidente del Consejo Europeo, al Presidente de la Comisión y la Comisión misma, en el ejercicio de sus respectivas funciones en el ámbito de la acción exterior ${ }^{39}$, lo cierto es que su principal misión será apoyar a la Alta Representante en el cum-

${ }^{35}$ Decisión del Consejo de 26 de julio de 2010 por la que se establece la organización y el funcionamiento del Servicio Europeo de Acción Exterior (2010/427/UE), Diario Oficial de la Unión Europea L 201, 3.8.2010, pp. 30-40.

${ }^{36}$ CONSEJO DE LA UE, Press release of the 3040th Council meeting (General Affairs), de 25 de octubre, de 2010, http://www.consilium.europa.eu/uedocs/cms_Data/docs/pressdata/ EN/genaff/117366.pdf.

37 Decisión 2010/427/UE, op. cit., note 35, Párrafos 1 y 2 del artículo 4.

38 Consejo de asuntos generales de la UE, nota de prensa, 15349/10 PRESSE 285 PR CO 28, de 25 de octubre de 2010, p. 10, http://www.consilium.europa.eu/uedocs/cms_Data/ docs/pressdata/EN/genaff/117366.pdf

39 Decisión 2010/427/UE op. cit., note 35, artículo 2.2. 
plimiento de su mandato, lo que significa ayudarla para que pueda contribuir con sus propuestas al desarrollo de la PESC, la PCSD y para asegurar la coherencia de la acción exterior, darle apoyo en su función como presidenta del Consejo de Asuntos Exteriores así como en cuanto Vicepresidenta de la Comisión.

El SEAE trabajará en estrecha colaboración con la Secretaría General del Consejo, con los servicios diplomáticos de los Estados miembros y con los servicios de la Comisión y otras instituciones y organismos, incluyendo el Parlamento Europeo y agencias como la OLAF, a la que se hace referencia expresa en la Decisión del Consejo por la que se crea el Servi$\mathrm{cio}^{40}$. En ésta, se precisa por lo demás que de las consultas que el SEAE deberá realizar con la Comisión se excluirán los asuntos relativos a la PCSD $^{41}$.

Un tercio del personal del SEAE deberá provenir de los servicios diplomáticos de los Estados miembros y al menos un $60 \%$ de los puestos deben ser cubiertos por funcionarios permanentes de la Unión Europea ${ }^{42}$. Todos ellos, funcionarios permanentes de la Unión y los agentes temporales procedentes de los servicios diplomáticos nacionales, tendrán los «mismos derechos y obligaciones y tendrán el mismo trato» ${ }^{43}$. La Decisión 2010/427, que establece el SEAE, permite además que este recurra «en determinados casos a un número restringido de expertos nacionales especializados en comisión de servicio ${ }^{44}$.

16. El SEAE descansará sobre dos pilares: la administración central y las Delegaciones de la Unión ${ }^{45}$ :

A) La administración central estará organizada en Direcciones generales. En algunas se integrarán los departamentos geográficos y temáticos. Habrá además una para asuntos administrativos, presupuestarios, de seguridad, comunicación y sistemas de información, encabezada por un Director General de Presupuestos y Administración. Y otra Dirección general en la que se integrarán la Dirección de Planificación de la Gestión de Crisis, la Capacidad Civil de Planeamiento y Ejecución, el Estado Mayor de la Unión Europea y el Centro de Situación de la Unión Europea ${ }^{46}$.

40 Decisión 2010/427/UE, op. cit., note 35, artículo 3. Vid. Http://ec.europa.eu/anti_fraud/ index_en.html (European Anti-Fraud Office).

${ }^{41}$ Ibid. artículo 3.2.

42 Ibid. artículo 6.9 .

${ }^{43}$ Ibid, artículo 6.7.

${ }^{44}$ Ibid, artículo 6.3.

45 Ibid, artículos 1, 4-5.

46 Vid. supra el parágrafo 9 de este trabajo. 
En la administración central se incluirán también un Servicio Jurídico, los Departamentos para relaciones inter-institucionales, diplomacia pública e información, auditoría interna y protección de datos personales, y asimismo (a propuesta del Parlamento Europeo) un Servicio de Planificación de Política Estratégica ${ }^{47}$.

B) El otro pilar del SEAE viene conformada por las Delegaciones de la Unión Europea en el exterior. La decisión de crear o cerrar una Delegación se adopta por el Alto Representante, de acuerdo con el Consejo y la Comisión $^{48}$.

17. En la medida en que toda una serie de departamentos de la Secretaría General del Consejo y de la Comisión, incluyendo las Delegaciones, se trasfieren en bloque al SEAE, unidades que trabajaban por separado en función de su adscripción a una institución u otra pasarán a hacerlo unidas y bajo la autoridad del Alto Representante. Entre nosotros, se ha puesto un sugerente ejemplo que me parece didáctico citar:

«el personal adscrito a la Dirección General E, dentro de la Secretaria General del Consejo, y las personas que trabajaban en la dirección para Europa del Este y Asia central pasan a trabajar en la misma unidad en que lo harán también los funcionarios de la Comisión que estaban trabajando en la Dirección General para las relaciones exteriores de la Comisión que se dedicaba a la misma área geográfica» ${ }^{49}$.

De este modo, la coherencia en las posiciones y decisiones de la Unión en política exterior debe ser el resultado natural (...).

Un reto importante es el que se deriva del cambio de naturaleza de las Delegaciones, que ya no representarán únicamente a la Comisión europea sino a la Unión en su conjunto. Los funcionarios que trabajen en las Delegaciones no se encargarán únicamente, por tanto, de ejecutar la dimensión exterior de las políticas comunitarias sino que deberán ocuparse también de la PESC y la PCSD. Se está ya reclutando a expertos en estas áreas para las Delegaciones, estando incluso abierta la discusión sobre la incorporación de agregados militares a las mismas. El 16 de septiembre de 2010, por lo demás, la Alta Representante dio a conocer los nombres de 29 de los Jefes de estas Delegaciones de la Unión, quienes

47 Decisión 2010/427/UE op. cit., note 35, artículo 4. Vid., también, el parágrafo 10 supra.

${ }^{48}$ Ibid, artículo 5.1.

49 CEBADA ROMERO, A., La Alta Representante de la Unión Europea: La primera Ministra integral de acción exterior, Documento de Opinión del Instituto Español de Estudios Estratégicos (IEEE), Ministerio de Defensa, Dirección General de Relaciones Institucionales, núm. 19/2010, noviembre, pp. 1-15 (p. 11) (http://www.ieee.es). 
ejercerán autoridad sobre todo el personal integrante de las mismas ${ }^{50}$; cinco de ellos son españoles y han sido destinados a las Delegaciones de Argentina, Angola, Guinea-Bissau, Namibia y (como segundo) de la República Popular China ${ }^{51}$.

Los departamentos vinculados a la PESC y a la PCSD se fusionan con los que venían trabajando en las relaciones exteriores. Y aunque en temas PESC y PCSD la adopción de decisiones sigue en manos del Consejo y los procedimientos varían en función de que estemos en un área o en otra, no debe menospreciarse el poder de propuesta que tiene la Alta Representante, lo que puede implicar que la creación de esta estructura administrativa en el ámbito de la acción exterior sea quizás una de las manifestaciones más contundentes de la supresión de los pilares llevada a cabo por el Tratado de Lisboa $(2007)^{52}$.

18. En la regulación que del SEAE se ha hecho, se ha omitido una cuestión de importancia, cual es la que se refiere a la formación de los diplomáticos ${ }^{53}$. La Decisión 2010/427/UE, de 26 de julio de 2010, que establece el SEAE ha fijado el plazo de un año para solución adecuada a este problema:

«Se tomarán medidas para dotar al personal del SEAE de una formación común adecuada, basada, en particular, en las prácticas y estructuras existentes en los ámbitos nacionales y de la Unión. El Alto Representante tomará las medidas oportunas a tal efecto antes de que finalice el año siguiente a la entrada en vigor de la presente Decisión» ${ }^{54}$

Se ha apuntado, asimismo, como otro de los problemas presentes en la configuración del SEAE efectuada el que, pese al principio de apertura de la Unión a la sociedad civil (artículo 11.2 del TUE y artículo 15.1 del TFUE) y de que, en particular, en el terreno diplomático hay organizaciones de la sociedad civil que están realizando una importante labor en el campo de la diplomacia privada, no se ha hecho ninguna referencia a la cooperación entre el SEAE y estas organizaciones. Omisión que no parece coherente ni con la intención de hacer de éste un Servicio adecuado a

50 Decisión 2010/427/UE, op. cit., note 35, artículo 5.2.

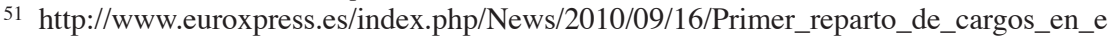
(16/12/2010); y http://www.eurosduvillage.eu/El-Servicio-Europeo-de-Accion-Exterior4067. html?lang=fr $(02 / 12 / 2010)$.

52 CEBADA ROMERO, A., La Alta Representante..., op. cit., nota 49, p. 12.

${ }^{53}$ La misma Alta Representante lo reconoce (Discurso de la AR/VP en el debate del PE sobre la acción exterior de la UE, 19 de octubre de 2010, http://europa.eu/rapid/ pressReleasesAction.do?reference=SPEECH/10/567\&format=HTML\&aged $=0 \&$ language $=$ EN\&guiLanguage $=$ en )

${ }^{54}$ Decisión 2010/427/UE, op. cit., nota 35, Artículo 6.12. 
las necesidades del siglo en que vivimos ni con la importancia que desde la Unión Europea se da a la mediación en lo que a gestión y prevención de conflictos se refiere ${ }^{55}$.

\section{Problemas claves del mismo}

19. A tres cuestiones concretas me voy a referir: la primera tiene que ver con los problemas que plantea su composición, atiende la segunda a la necesidad que puede surgir de delimitación de las respectivas competencias que en su funcionamiento deban tener Unión y Estados miembros, refiriéndose, en fin, la tercera a las implicaciones que su puesta en marcha supondrá para nuestro país.

\section{Composición del SEAE}

20. Sobre la composición del Servicio, que necesariamente debe contar con miembros procedentes de los servicios del Consejo y la Comisión así como de los servicios diplomáticos de los Estados miembros, se barajaron dos tesis ${ }^{56}$ :

- La más restrictiva preconizaba un Servicio claramente centrado en cuestiones de política exterior pura y dura, esto es, de cuestiones del segundo pilar tal y como este se contempla en el Derecho hasta hace poco vigente. Según esta perspectiva, solo los órganos que trabajan actualmente en el ámbito concreto de la PESC (incluida, sí, la PESD) integrarían el Servicio.

- La tesis más amplia, por el contrario, propugnaba un Servicio Europeo mucho más ambicioso, dado que incluiría todas las Direcciones generales de la Comisión que abordan la dimensión exterior de ciertas políticas comunitarias, esto es, no solo la de Relaciones Exteriores sino también las Direcciones Generales de Desarrollo, Ampliación, Ayuda Humanitaria y la Oficina de Cooperación, excluyéndose únicamente la Dirección General de Comercio; cabe señalar en este sentido que el Informe de situación (2005) reveló la existencia

55 CEBADA ROMERO, A., La Alta Representante..., op. cit., nota 49, pp. 12-13. También, de la misma autora: «Hacia la construcción descentralizada de la paz: una oportunidad para la sociedad civil, para el Derecho internacional y para la Unión Europea» en Revista de Derecho Comunitario Europeo, 2010, núm 35, pp. 1-44.

56 De «minimalista» y «maximalista» se las califica (FERNÁNDEZ SOLA, N. El Servicio Europeo..., op. cit., nota 5, pp. 12, 13. 
de «un consenso en que no debería incluirse la política comercial» ${ }^{57}$. Por el Consejo, formarían parte del Servicio, y además de la Dirección General E y la Unidad Política, el Estado Mayor de la Unión Europea y el Centro de Situación.

Aun entendiendo que la tesis restrictiva era más cautelosa y aún prudente en un tema que va a plantear muchos problemas, no parecía coherente con la decisión que tomara el Tratado Constitucional (2004), y el de Lisboa, aunque suavizándola, ha mantenido ${ }^{58}$, de dotar a la acción exterior de la Unión de mayor visibilidad, coherencia y eficacia: más «visibilidad» en cuanto la Unión Europea y la Comunidad Europea actuales serán sustituidas por una «superestructura» única, la Unión Europa, que verá además regulada su acción exterior de modo más organizado, tanto en el TUE como en el TFUE; mayor coherencia se pretende precisamente con la creación de la figura del Alto Representante (en el Tratado Constitucional, Ministro de Asuntos Exteriores de la Unión en su conjunto), que será el responsable de la acción exterior tanto en el Consejo como en la Comisión, ayudado por una administración bajo sus órdenes, el SEAE; y más eficacia como consecuencia, amén de otras posibles consideraciones, de esa Unión Europea más visible y coherente.

Solo una composición suficientemente amplia de este Servicio permitirá al Alto Representante ejercer con coherencia y eficacia su labor como responsable de la acción exterior en su conjunto y en sus diversas facetas de la Unión Europea. Cabe añadir en este sentido que «la opinión mayoritaria de los Estados miembros», y citamos palabras textuales del Informe de situación (2005), se situaría en un punto intermedio entre las posiciones minimalista y maximalista referidas, lo que comportaría un SEAE formado por la DGE, la Unidad Política del Consejo y probablemente por el Estado Mayor de la Unión así como, del lado de la Comisión por su Dirección General de Relaciones exteriores; había más dudas y reticencias a incluir también el personal del Centro de Situación ${ }^{59}$

La Decisión 2010/427/UE, de 26 de julio de 2010, del Consejo incluye todo lo que la posición que se ha llamado maximalista pedía respecto de los servicios del Consejo, esto es, la Unidad Política, la PCSD y las estructu-

57 Servicio Europeo de Acción Exterior. Informe conjunto... op. cit., nota 14, p. 4 (apartado número 8).

58 Aquél dedicó un título único, en su Parte III, (el V) al conjunto de la acción exterior de la Unión; el Tratado de Lisboa (2007) deja la PESC y la PCSD en el TUE y en el TFUE agrupo (en su Parte quinta) la dimensión exterior de diversos ámbitos materiales que se hallaban dispersos en el TCE. Esta situación, entienden ALDECOA LUZÁRRAGA, F. y GUINEA LLORENTE, M., «supone un claro retroceso» (La Europa que viene..., op. cit., nota 6, p. 217).

59 Servicio Europeo de Acción Exterior. Informe de servicio conjunto... op. cit., nota 14, p. 4 (apartado número 8). 
ras de gestión de crisis (incluyendo al Estado Mayor de la Unión Europea [EMUE] y el Centro de Situación [SITCEN]) y la Dirección General E. En cuanto a los servicios de la Comisión, el SEAE creado no «abduce» todo lo que los maximalistas deseaban pero sí va más allá de las tesis (mayoritarias) que se conformaban con un justo medio, dado que el Consejo transfiere al SEAE, con excepciones puntuales en algún caso de cierto tipo de personal, no solo la Dirección General de las Relaciones Exteriores y el Servicio Exterior sino asimismo la Dirección General de Desarrollo ${ }^{60}$.

21. En todo caso, una composición amplia del Servicio generará a su vez problemas de diverso tipo a los que habrá que hacer frente. Como el conectado con el dato de que al superar con mucho el número de funcionarios integrado en los servicios de la Comisión al de los que hacen lo propio en los del Consejo, surgía la interrogante de si no sería conveniente concretar el peso que cada una de estas instituciones habría de tener en el Servicio Europeo de Acción Exterior. ¿Cómo, además, se seleccionarían sus integrantes?

A) En relación con la primera de estas cuestiones, la Cámara de los Comunes del Reino Unido en particular consideró esencial que la composición de este Servicio no otorgara a la Comisión, la institución supranacional, un peso excesivo en detrimento del Consejo, la institución que representa a los Estados ${ }^{61}$. Estos temores fueron determinantes al dejar fuera de la composición del SEAE los servicios de la Comisión encargados de la política comercial, por más que estos tengan que ver con la acción exterior de la Unión.

Por otra parte, parecería razonable precisar el número de miembros del Servicio que habrán de proceder de los servicios diplomáticos nacionales. En un análisis reciente, su autora ha sostenido (con base en informaciones proporcionadas por altos funcionarios de la Comisión, del Consejo y de la Representación Permanente de España), que una fórmula equilibrada que podría contar con el indispensable apoyo de los Estados miembros nos llevaría a «una composición inicial de 1.000 funcionarios de la Comisión, 200 del Consejo y 2000 de los Estados miembros, que con el tiempo pudiera alcanzar los 6.000 efectivos» $^{62}$.

La decisión del Consejo, de 26 de julio de 2010, ha respondido a la mayoría de estas inquietudes. De este modo, su artículo 6.9 determina que «al

${ }^{60}$ La decisión 427 del Consejo relaciona en su Anexo «Los servicios y funciones que se transferirán al SEAE» (Diario Oficial de la Unión Europea L 201, 3 de agosto de 2010, pp. 39-40).

${ }^{61}$ HOUSE OF COMMONS, UK Parliament (2008), Foreign Policy Aspects of the Lisbon Treaty, Third Report, 20/01/2008, Foreign Affaire Committee, párrafos 179, 182. http:// www.parliement.the-stationery-office.co.uk/pa/cm/cmfaff.htm (última consulta 12/12/2010)

${ }^{62}$ FERNÁNDEZ SOLA, N., El Servicio Europeo..., op. cit., nota 5, p. 13 y nota 1 de la p. 1. 
menos un tercio de la plantilla total del SEAE» procederá de los servicios diplomáticos de los Estados miembros y «al menos el 60 por ciento» estarán representados por «funcionarios permanentes de la Unión». Se habrá reparado en que no se ha considerado necesario proceder expresamente y de manera formal a un reparto más concreto entre Comisión y Consejo (...). Esta situación nos lleva a que aunque en su etapa inicial el SEAE no superará en ningún caso los 3.000 funcionarios, más adelante podrá llegar a contar hasta con $8.000^{63}$.

B) Cómo seleccionar al personal integrante del Servicio es una más de las cerezas prendidas en este racimo. Los trabajos preparatorios acometidos no eran proclives a fijar con carácter previo porcentajes o cuotas nacionales: así, el Informe de Situación elaborado en el 2005 por el Alto Representante y la Comisión solo especificó la necesidad de asegurar «un equilibrio geográfico adecuado, aunque evitando que se establezca un sistema de cuotas»; y lo mismo sostuvo un Informe del Consejo posterior $(2008)^{64}$. Resultará en todo caso necesario concretar cuales habrán de ser los criterios para su selección. Había al menos dos opciones posibles:

- Una pasaría por la realización de un concurso u oposición, a decidir, en cuanto a los méritos de los candidatos, por una comisión que incluyeran representantes de las instituciones de la Unión y de los Estados miembros.

- La otra fórmula que se ha manejado pasaría por la propuesta de candidatos por cada Estado (y eventualmente, si así se decidiera, del Consejo y la Comisión) y la decisión final de un órgano reducido del entorno del Alto Representante, que podría de este modo formar un Servicio de acuerdo con los méritos y competencia de los candidatos pero también de su confianza. El Informe de situación (2005) constató «un amplio acuerdo» sobre la importancia de los méritos en la selección del personal, según procedimientos «en los que el Ministro [se refiere al que el Tratado Constitucional de 2004 llamaba Ministro de Asuntos Exteriores de la Unión Europea] desempeñaría un papel primordial, que incluiría su aprobación de las decisiones finales ${ }^{65}$.

63 Según los datos que proporciona el entonces diputado socialista en el Parlamento Europeo y hoy Ministro del Gobierno Ramón Jáuregui, «el 1 de enero de 2011, un total de 1.525 funcionarios de la Comisión y la Secretaria General del Consejo serán transferidos al SEAE y se crearán 100 nuevos puestos» (El Parlamento Europeo: un actor decisivo..., op. cit.,. nota 30, p. 5). Al número citado, claro, habrá que sumar el de los miembros de los servicios diplomáticos nacionales (...).

64 Servicio Europeo de Acción Exterior. Informe conjunto..., op. cit., nota 14, p. 6 (apartado número 14); External Action Service. Contribution by Council Secretariat Officials, 2008.

65 Servicio Europeo de Acción Exterior. Informe de situación conjunto..., op. cit., nota 14, cit., p. 6 (apartado núm. 14). 
Parece claro que la primera opción es más rigurosa pero también más costosa y lenta. El Consejo ha decidido finalmente que los méritos sean un factor importante en el proceso de selección, pero este a fin de cuenta lo fijará la Alta Representante:

«El Alto Representante establecerá los procedimiento de selección del personal del SEAE, que se llevará a cabo por un procedimiento transparente basado en los méritos, con el objetivo de contar con los servicios de un personal con el máximo nivel de capacidad, eficacia e integridad, garantizando un equilibrio geográfico adecuado y un reparto equitativo entre hombres y mujeres, y la presencia significativa en el SEAE de nacionales de todos los Estados miembros $(\ldots) »^{66}$.

El Informe de situación (2005), por lo demás, daba cuenta de que «la práctica totalidad» de los Estados miembros consideraba que el personal nacional en el Servicio Europeo debía estar compuesto «por agentes personales y no por expertos nacionales en comisión de servicios, garantizando así un estatuto único y condiciones de trabajo idénticas para toda la plantilla del Servicio Europeo de Acción Exterior» ${ }^{67}$. Así se ha decidido como regla general, aunque «si fuera necesario» el SEAE podrá recurrir «en determinados casos» a expertos nacionales especializados en comisión de servicio en «un número restringido» ${ }^{68}$.

\section{Las Delegaciones de la Unión}

22. Una de las decisiones que alcanzó «un amplio consenso» en el Consejo y que reflejó el Informe de Situación (2005) es que la red de Delegaciones con la que en la actualidad cuenta la Comisión, instrumento indispensable a través del cual la Comunidad Europea ha ejercido un genuino ius legationis, se transformarán en «delegaciones de la Unión» y formarán parte del SEAE bajo autoridad del Alto Representante ${ }^{69}$. Por otra parte, en el mismo Informe se refleja que «la mayoría de los Estados miembros» se manifestaron a favor de la idea de que estas delegaciones

66 Decisión 2010/427/UE op. cit., nota 34, artículo 6.8.

67 Ibid, p. 6 (apartado núm. 13).

68 Ibid., artículo 6.3. El párrafo 2 del mismo deja claro que a todos los integrantes del SEAE (ya sean funcionarios o agentes de la Unión Europea ya miembros del personal de los servicios diplomáticos de los Estados miembros en cuanto agentes temporales) se les aplicará el Estatuto de los Funcionarios de la Unión Europea y el régimen aplicable a los otros agentes de la Unión( $($ ROA»),

${ }^{69}$ Servicio Europeo de Acción Exterior. Informe de situación conjunto... op. cit., nota 14, p. 5 (apartado núm.11). 
«podrían asumir cometidos adicionales tales como la protección consular y $\operatorname{los}$ visados» ${ }^{70}$.

23. El artículo 20 del TCE reconocía a los ciudadanos de la Unión, es decir, a los nacionales de los Estados miembros de la misma, el derecho a acogerse en el territorio de un tercer país en el que el Estado del que es nacional no cuenta con representación, «a la protección de las autoridades diplomáticas y consulares de cualquier Estado miembro, en las mismas condiciones que los nacionales de dicho Estado»; y se añadía que los Estados miembros establecerán entre sí las normas necesarias y entablarán las negociaciones internacionales para garantizar dicha protección ${ }^{71}$. Por su parte, el también artículo 20 del TUE disponía en términos generales la cooperación entre las misiones diplomáticas y consulares de los Estados miembros y las delegaciones de la Comisión en terceros países para contribuir a la ejecución del artículo 20 del TCE que he mencionado.

En aplicación de estas disposiciones, los representantes de los Estados miembros, reunidos en Consejo, adoptaron el 19 de diciembre de 1995 la decisión 95/55372. En ella, los Estados miembros especificaban los casos en los que sus misiones diplomáticas o consulares podrían prestar su protección a nacionales de otros Estados miembros que no contaran con representación propia en un tercer país. La protección, en concreto, consistiría en:

«a) la asistencia en casos de fallecimiento;

b) la asistencia en casos de accidente o enfermedad grave;

c) la asistencia en casos de arresto o detención;

d) la asistencia a víctimas de actos de violencia;

e) el socorro y la repatriación de nacionales de la Unión en dificultad» ${ }^{73}$.

70 Ibid, p. 6 (apartado número 12).

${ }^{71}$ Sobre los antecedentes que llevaron al artículo 20 del TCE vid. los comentarios del que fuera Embajador de España ALVARGONZÁLEZ SANMARTIN, F., «Protección diplomática y consular» en ÁLVAREZ CONDE, E. y GARRIDO MAYOL, V. (dirs.), Comentarios a la Constitución Española. Libro II (Los derechos y libertades), Tirant lo Blanch, Valencia, 2004, pp. 1.467-1.490 (pp. 1.470 ss.).

${ }_{72}$ Relativa a la protección de los ciudadanos de la Unión Europea por las representaciones diplomáticas y consulares (Diario Oficial de la Unión Europea L 314, de 28 de diciembre de 1995). La decisión que, en virtud de su artículo 8, debía entrar en vigor «cuando todos los Estados miembros hayan notificado a la Secretaria General del Consejo la conclusión de los procedimientos exigidos por sus respectivos ordenamientos jurídicos», lo hizo finalmente en mayo de 2002 (Informe de la Comisión. Cuarto informe sobre la ciudadanía de la Unión [1 de mayo de 2001-31 de abril de 2004], Bruselas, 26 de octubre de 2004 [COM/2004/0695 final], apartado 3.4 [disponible en http://eur-lex.europa.eu/smartapi/cgi/sga_doc]).

73 Artículo 5.1 de la Decisión 95/553. Para un comentario sobre cada uno de estos supuestos, ALVARGONZÁLEZ SANMARTÍN, F., «Protección ...», op. cit., nota 71, pp. 1.484 ss. 
La doctrina mayoritaria fue de la opinión de que no nos encontrábamos ante una protección diplomática (que autoriza a los Estados a presentar una reclamación formal de responsabilidad ante el gobierno de otro por haber quebrantado el Derecho internacional en la persona de uno de sus nacionales), ni tampoco, estrictamente hablando, de una protección consular genuina (en la que por lo común el jefe de la oficina consular de un Estado reclama al órgano de otro la comisión de una violación del Derecho interno o internacional en perjuicio de uno de sus nacionales), sino de una mera protección o asistencia consular por razones humanitarias ${ }^{74}$. Todos los autores estaban además de acuerdo en que incluso así era necesario un acuerdo entre el país anfitrión y el Estado miembro de la Unión que pretendía proteger a un no nacional para que ello fuera posible (de ahí, recuérdese, que el artículo 20 del TCE determinaran que «los Estados miembros... entablarán las negociaciones internacionales requeridas para garantizar dicha protección»).

La práctica seguida por los Estados miembros, como el documento final del Proyecto CARE demostrará ${ }^{75}$, no ha sido uniforme en la aplicación de las disposiciones de Derecho primario y de Derecho derivado mencionadas. Y no lo ha sido en aspectos varios ${ }^{76}$ :

- Algunos Estados miembros (como el Reino Unido) solo aplican, en cuanto a la protección consular prevista en el Derecho de la Unión para los nacionales de otros países miembros, las supuestos específicos de la decisión 95/553. Otros, sin embargo, prestan la asistencia consular más allá de los casos relacionados en el artículo 5 de la decisión citada. Así lo hacen Austria, Bélgica, Hungría y Luxemburgo (en tratados internacionales concertados por esos países con terce-

${ }^{74}$ Véase la relación de los autores que se expresaron en este sentido mencionada, por ejemplo, en GUTIÉRREZ ESPADA, C. y CERVELL HORTAL, M. ${ }^{\mathrm{a}}$ J., La adaptación al Tratado de Lisboa (2007) del sistema institucional decisorio de la Unión, su acción exterior y personalidad jurídica, Comares, Granada, 2010, pp. 88-89 (nota 202).

75 El Proyecto CARE (Consular and Diplomatic Protection Legal framework in the EU Menber States, Project number: JLS/2007/FRC-1/50 30-CE-0226854/00-31), financiado por el Programa sobre Derechos Fundamentales y Ciudadanía de la Comisión, pretende ofrecer cual el Derecho y la práctica de los 27 Estados miembros de la Unión en lo relativo a la protección diplomática y consular de sus nacionales en el mundo (incluyendo a los nacionales de otros Estados miembros). A tal efecto se han designado Relatores para cada país (en el caso de España esta labor fue realizada en su fase final y definitiva por el profesor de Derecho Internacional de la Universidad de Murcia Jorge Juan Piernas López). El muy extenso Documento Final, ya en fase muy avanzada (deliverable 3.1, versión 1.3, december 2010), aunque todavía confidencial, incluirá probablemente un Estudio Introductorio, un capítulo de Análisis Comparativo, que se cerrará con un Sumario y un capítulo final de Conclusiones y Recomendaciones

${ }^{76}$ Lo que el Proyecto CARE, op. cit., nota 75, probablemente, confirmará. 
ros) o la República Checa, Estonia, Latvia, Lituania, Suecia o España (en aplicación de las disposiciones nacionales que han adoptado para la ejecución del antiguo artículo 20 del TCE).

- Solo Italia y Portugal incluyen en los tratados que conciertan con terceros cláusulas que tienen como objetivo extender el ejercicio de su protección diplomática o consular a nacionales de otros Estados miembros. La mayoría de estos se limita a notificar a los terceros países que lo harán llegado el caso. Naturalmente, la notificación no basta, pues solo un tratado internacional en el que el tercero prestase su acuerdo a esta eventualidad sería suficiente, en virtud del Derecho Internacional que rige las relaciones diplomáticas y consulares.

- Menos de la mitad de los Estados miembros consideran que la protección diplomática o consular en un derecho del ciudadano jurídicamente protegido. Algunos de ellos lo reconocen así incluso en sus normas de rango constitucional, otros solo mediante disposiciones de rango legislativo.

En todo caso, de aceptarse la propuesta del Informe de Situación (2005), las Delegaciones de la Comisión, que se habrían convertido ya en Delegaciones de la Unión Europea y estarían integradas en el SEAE, podrían pasar a ejercer directamente la protección consular que los Estados miembros venían prestando a nacionales de otros Estados miembros cuyos países no contaran con representación diplomática o consular. Habría que precisar, de ser así, en todo caso, si dicha posibilidad dependería o no de una petición de los Estados miembros o si el particular afectado podría dirigirse directamente sin más a una de las Delegaciones de la Unión (...). Por lo demás, y de acuerdo con el Derecho primario vigente, la eventual protección consular que directamente pudieran prestar las Delegaciones de la Unión solo sería posible en el supuesto de nacionales de los Estados miembros que con contasen en el país tercero con representación diplomática o consular y, desde luego, que existiese un acuerdo entre la Unión y el tercer país en el que esta posibilidad se contemplara por ambas partes.

24. Ya el Tratado de Lisboa (2007) modificó aspectos de esta situación, como lo ha hecho igualmente la decisión del Consejo de 26 de julio de 2010 sobre el establecimiento del SEAE.

El Tratado de Lisboa, de una parte, mantiene las disposiciones de los antiguos artículos 20 del TUE y del $\mathrm{TCE}^{77}$, añadiendo expresa y literalmente la competencia del Consejo para adoptar, previa consulta con el Parlamento Europeo y mediante procedimiento legislativo especial, directivas

77 Artículos 35 del TUE reformado y 23 del TFUE. 
que coordinen las legislaciones nacionales y establezcan las pautas de cooperación necesarias que faciliten la protección que a los ciudadanos europeos se concede en el Derecho primario de la Unión ${ }^{78}$.

La Decisión 2010/427/UE, de 26 de julio, del Consejo determina en efecto, como se pedía en el Informe de Situación (2005), la inclusión en el SEAE y bajo la responsabilidad de la Alta Representante, de las Delegaciones de la Unión. Y se dice:

«las delegaciones de la Unión, de conformidad con el artículo 35, párrafo tercero, TUE, apoyarán a los Estados miembros, a petición de éstos, en sus relaciones diplomáticas y en su función de prestación de protección consular a los ciudadanos de la Unión en países terceros, basándose en la neutralidad en lo que se refiere a los recursos» ${ }^{79}$.

25. En conclusión: Uno, no todos los Estados miembros ejercen la protección consular de nacionales de otros miembros con el mismo alcance, yendo algunos más allá de lo que la directiva en vigor les exige.

Dos, las Delegaciones de la Unión no parece que puedan ejercer esta llamada protección consular de ciudadanos de la Unión si no es a petición de los Estados miembros (no queda especificado en la Decisión 2010/427 si esta petición debe proceder necesariamente del Estado miembro de nacionalidad del candidato a la protección y que no cuenta con representación en el tercer país), Si esta interpretación es correcta, y la misma se basa en la misma letra del la Decisión 2010/427, el avance sobre la situación actual es muy limitado y queda a años luz de las expectativas de algunos.

Tres, parece más que razonable la aplicación del párrafo segundo del artículo 23 del TFUE, esto es, la adopción de una directiva que coordine el ejercicio de la protección consular por los Estados miembros de la Unión a nacionales de otros estados miembros. En ella, deberían tenerse en cuenta al menos los puntos siguientes:

- El contenido de la futura directiva no debería limitarse a los supuestos de mera asistencia consular humanitaria previstos en la directiva de 1995. La legalización de documentos, documentos sobre estatuto personal y familiar, declaración de matrimonio, certificaciones de muerte o nacimiento..., podrían ser algunos ejemplos. No será fácil. Recuérdese que el Reino Unido se opuso a que la Decisión 2010/427, que estableció el SEAE, habilitase a las Delegaciones de la Unión para el ejercicio de algunas funciones consulares ${ }^{80}$.

78 TFUE, artículo 23, párrafo segundo.

79 Decisión 2010/427/UE, op. cit., nota 34, Artículo 5.10 (la cursiva es mía).

80 Vid. supra el parágrafo 10 de este trabajo. 
- Debería incluso estudiarse la posibilidad de incluir en su texto el caso específico en que nacionales de Estados miembros de la Unión sufrieran torturas en un país tercero. La tortura es un crimen que prohíbe el Derecho Internacional general. Debería permitirse a otros Estados miembros o incluso a las Delegaciones de la Unión asumir la protección de esas personas en tal caso cuando el Estado de su nacionalidad no contarse con representación diplomática y consular. De ser así y dada la naturaleza del hecho ilícito, estaríamos hablando de algo más que del ejercicio de una mera protección consular.

- Si la futura directiva no pudiese llegar a este extremos, sí sería de interés que al menos se dejase claro en su texto que los ciudadanos de la Unión tienen derechos, de conformidad con el artículo 20 del TFUE pero también del artículo 48 de la Carta de Derechos Humanos de la Unión Europea, no solo a protección consular sino también diplomática y que esta última podrá ser objeto de nuevas medidas normativas cuando se considere conveniente ${ }^{81}$.

Cuatro, los Estados miembros debería hoy más que nunca (quiero decir tras los avances del Tratado de Lisboa en esta cuestión), y como Italia y Portugal vienen haciendo desde hace unos años, incluir en sus acuerdos bilaterales con terceros países una cláusula que permita el ejercicio de la protección consular por el Estado miembro parte del acuerdo de nacionales de otros Estados miembros de conformidad con el artículo 23 del TFUE. Como debe hacerlo también el Alto Representante respecgto de las Delegaciones de la Unión.

\section{Implicaciones para España}

26. La puesta en marcha del SEAE puede llevar a reflexionar, utilitatis causa y por consideraciones económicas, sobre la eventual supresión o reducción de personal de embajadas o consulados allí donde hubiere una Delegación de la Unión Europea. En este sentido, parece razonable llevar a cabo lo que se ha llamado una «reducción selectiva» ${ }^{82}$, esto es, man-

81 Es más que probable que el Proyecto CARE (Consular,... op. cit., nota 75) se aborde esta cuestión, y se formulen propuestas concretas sobre el contenido de una futura directiva.

82 PORTELA, C., El Servicio de Acción Exterior Europeo: Implicaciones para la reforme del Servicio Diplomático español, documento de Trabajo OPEX 2009, Fundación Alternativas, pp. 1-42 (p. 27) (http://www.falternativas.org/opex/documentos-opex/documentosde-trabajo). 
tener la representación española a todos los efectos en países de importancia prioritaria para España (particularmente en el terreno comercial); destacar diplomáticos nacionales en puestos de responsabilidad en representaciones conjuntas con las delegaciones de la Unión para aquellos países que tengan para España una importancia relativa y, en fin, cerrar las embajadas españoles en países de importancia, para el nuestro, secundaria o marginal.

En un documento reciente, en el que se efectúa una propuesta estratégica para que nuestro país esté entre los grandes, el Real Instituto Elcano demostraba, manejando «datos empíricos "objetivos"» sobre nuestra posición económica actual y sobre otros factores (políticos y sociales), que «en la actualidad España se encuentra entre los 10-12 países más importantes del mundo» y proponía aprovechar la presente crisis económica y financiera internacional («haciendo de la necesidad virtud») para reforzar nuestra posición entre los Estados más influyentes del planeta. Para lograrlo, es decir, para conseguir insertar a España de forma estable en el nuevo orden internacional en un lugar que le permita desplegar todo su potencial como actor global, el Real Instituto Elcano consideraba que, además de llevar a cabo las reformas estructurales necesarias a nivel interno, nuestro país debe dotarse:

«de mayor claridad estratégica y [dotar]de mayor fortaleza y efectividad a nuestra acción exterior» ${ }^{83}$.

Por otra parte y unos meses antes, el Presidente del Gobierno anunciaba las grandes líneas de su política exterior para este su segundo mandato. En su intervención, afirmó que:

«hoy el mundo necesita a una Europa más fuerte: (...) esa Europa capaz de tomar decisiones con eficacia y de pesar en el mundo $(\ldots) »^{84}$.

27. Con estos presupuestos, parece lógico pensar que la posición española sea la de contar con una participación en el SEAE de peso y del nivel más alto posible. Y de ser así, parece razonable considerar el que deberían incrementarse, sobre la actual situación, los efectivos y medios de los servi-

83 España ante el G-20: una propuesta estratégica sobre su inserción en la nueva gobernanza global, Informe del Real Instituto Elcano de Estudios Internacionales y Estartégicos, 31/03/2009, pp. 3-6, 19 (www.realinstitutoelcano.org).

${ }^{84}$ RODRÍGUEZ ZAPATERO, J.L., «En interés de España: una política exterior comprometida», texto de la conferencia pronunciada por el Presidente del Gobierno en el Museo del Prado el 16 de junio de 2008, acto organizado por el Real Instituto Elcano con la colaboración de CIDOB, FRIDE, ICEI e INCIPE, ARI núm. 55, julio de 2008, p. 8. 
cios españoles de acción exterior hasta alcanzar, o al menos acercarse en lo posible, a los que tienen otros Estados miembros de peso análogo y similares intereses a los nuestros en estos temas.

Y si estos razonamientos son correctos, resultará también inevitable el que deba incrementarse la preparación de nuestros futuros diplomáticos y cónsules en los asuntos propios de la Unión Europea y su Ordenamiento jurídico, muy en particular de los que posean una clara dimensión exterior. En esa labor, la Escuela Diplomática resulta, sin duda, imprescindible. El diseño de nuevos módulos o el fomento del twinning (envío de funcionarios a un administración receptora para desempeñar en ella su labor en la misma área de la que era responsable en su administración de origen) podrían ser ideas de interés. Como lo seria también, probablemente, el plantearse una reconsideración, am menos parcial, del métodos de acceso a la Carrera Diplomática $^{85}$.

\section{En suma (...)}

28. El SEAE ya está aquí y sin embargo la realidad de una auténtica política exterior común de la Unión sigue tan lejana y difusa como estaba. El miedo de los Estados miembros a la pérdida de soberanía es aún muy grande, como las Declaraciones 13 y 14 aprobadas por la CIG que generó el Tratado de Lisboa (2007) ponen claramente de manifiesto ${ }^{86}$. El Tratado de Lisboa pretendía dotar a la Unión de una PESC, incluyendo la PCSD, aptas para el siglo XXI. Pasado un año ya desde su entrada en vigor, no se ve aún como ello podrá conseguirse (...).

¿En qué ha variado la imagen que desde fuera se tenía de la Unión Europea?, un gigante económico, pero una enano en política exterior; como no sea para que, por la crisis financiera y económica, la estatura y la fortaleza del gigante se vean disminuidas (...).

29. Solo si la Unión Europea se desprende de esa «paralizante estrechez de miras» de la que Javier Solana hablaba en su discurso de recepción del Premio Carlomagno (2007), podrá convertirse en un actor global de las relaciones internacionales.

Solo si la Comisión renuncia a una posición de excesivo protagonismo en este tema y solo si los Estados miembros con más experiencia, capacidad de acción e influencia en la política exterior se implican decisivamente o, como el Sr. Solana Madariaga decía, «mandan a sus mejores hombres»,

85 Vid. sobre estas cuestiones el sugerente análisis de PORTELA, C., El Servicio de Acción Exterior..., op. cit., nota 82, pp. 29-37

86 Vid. supra el parágrafo 2 de este trabajo. 
el SEAE será de verdad eficaz y útil en aquel objetivo. Esto es, será algo más que la espléndida fachada que su denominación nos ofrece, pues entonces albergará en su seno los mecanismos que irán haciendo de la Unión un «actor global, hablando con una sola voz» y también un «factor decisivo en la paz y estabilidad mundiales» ${ }^{87}$.

87 Todas las frases entrecomilladas son del que fuera Alto Representante de la Unión para la PESC (Reivindicación de la Política..., op. cit., nota 17, p. 147). Que su cita sirva para recordar su labor al frente de la política exterior de la Unión en los últimos años. 